\title{
Seedless Polyol Synthesis and CO Oxidation Activity of Monodisperse (111) and (100)-Oriented Rhodium Nanocrystals in Sub-10 nm Sizes
}

Yawen Zhang, ${ }^{\dagger *}$ Michael E. Grass, ${ }^{\star}$ Wenyu Huang, ${ }^{\ddagger}$ and Gabor A. Somorjai* ${ }^{\star *}$

${ }^{\dagger}$ College of Chemistry and Molecular Engineering, and the State Key Lab of Rare Earth Materials Chemistry and Applications \& PKU-HKU Joint Lab in Rare Earth Materials and Bioinorganic Chemistry, Peking University, Beijing 100871, China

* Department of Chemistry, University of California, Berkeley, California 94720, and the Chemical and Materials Sciences Divisions, Lawrence Berkeley National Laboratory, 1 Cyclotron Road, Berkeley, California 94720

*Corresponding authors. E-mail: ywzhang@pku.edu.cn; somorjai@berkeley.edu. 


\begin{abstract}
Monodisperse sub-10 nm (6.5 nm) sized Rh nanocrystals with (111) and (100) surface structures were synthesized by a seedless polyol reduction in ethylene glycol, with poly(vinylpyrrolidone) as a capping ligand. When using $\left[\mathrm{Rh}(\mathrm{Ac})_{2}\right]_{2}$ as the metal precursor, (111)-oriented $\mathrm{Rh}$ nanopolyhedra containing $76 \%$ (111)-twined hexagons (in 2D projection) were obtained; whereas, when employing $\mathrm{RhCl}_{3}$ as the metal precursor in the presence of alkylammonium bromide, such as tetramethylammonium bromide and trimethyl(tetradecyl)ammonium bromide, (100)-oriented Rh nanocubes were obtained with $85 \%$ selectivity. The $\{100\}$ faces of the $\mathrm{Rh}$ nanocrystals are stabilized by chemically adsorbed $\mathrm{Br}$ - ions from alkylammonium bromides, which led to (100)-oriented nanocubes. Monolayer films of the (111)-oriented Rh nanopolyhedra and (100)-oriented $\mathrm{Rh}$ nanocubes were deposited on silicon wafers in a Langmuir-Blodgett trough to make model 2D nanoarray catalysts. These nanocatalysts were active for $\mathrm{CO}$ oxidation by $\mathrm{O}_{2}$, and the turnover frequency was independent of nanoparticle shape, consistent with that previously observed for $\mathrm{Rh}(111)$ and $\mathrm{Rh}(100)$ single crystals.
\end{abstract}




\section{Introduction}

Monodisperse shape-controlled noble metal nanocrystals have considerable scientific and technological significance in the catalytic field. ${ }^{1,2}$ Precise shape control may help reveal fundamental catalytic properties of nanoscale materials in comparison with their bulk counterpart (single crystals), as well as provide tunable catalytic activity and selectivity for nanocatalysts in many technologically important heterogeneous

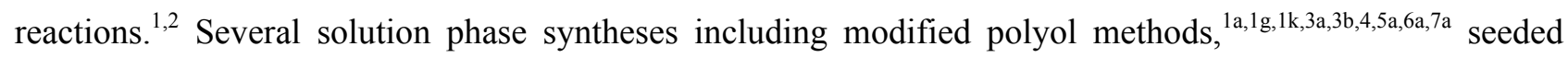
growth by polyol reduction, ${ }^{7 \mathrm{~b}, \mathrm{c}}$ thermolysis of organometallics, ${ }^{1 \mathrm{f}, 7 \mathrm{~d}, 7 \mathrm{e}}$ and micelle techniques ${ }^{3 \mathrm{cc}, 5 \mathrm{~b}, 6 \mathrm{~b}}$ have been developed to kinetically and/or thermodynamically manipulate the shape of noble metal nanocrystals (e.g. $\mathrm{Pt},{ }^{1 \mathrm{a}, 1 \mathrm{f}, 1 \mathrm{k}, 3} \mathrm{Pd},{ }^{4} \mathrm{Ag},{ }^{5} \mathrm{Au}^{6}$ and $\left.\mathrm{Rh}^{1 \mathrm{~g}, 7}\right)$, by regulating the relative growth rates along low-index plane directions (i.e. $<100>$ and $<111>$ ).

$\mathrm{Rh}$ nanocatalysts have been employed in many heterogeneous reactions including hydrogenation, ${ }^{8 \mathrm{a}, 8 \mathrm{e}}$ hydroformylation, ${ }^{8 \mathrm{~b}}$ hydrocarbonylation, ${ }^{8 \mathrm{c}}$ and combustion. ${ }^{8 \mathrm{~d}}$ Shape control of $\mathrm{Rh}$ nanocrystals provides a route for probing how faceting on the nanoscale influences catalytic activity and selectivity. Several groups have been engaged in size and shape control of Rh nanocrystals via various solution chemistry approaches. By a polyol approach, Xia's group prepared Rh multipods that demonstrate useful SERS activity. ${ }^{7 \text { a }}$ With a polyol seeded growth, the Somorjai and Tilley groups obtained crystalline Rh multipods, cubes, horns and cuboctahedra. $^{7 b, c}$ Through organometallic routes, Son and coworkers synthesized near-monodisperse tetrahedral $\mathrm{Rh}$ nanocrystals (displaying shape-dependent catalytic hydrogenation of arenes), ${ }^{7 \mathrm{~d}}$ and ultrathin $\mathrm{Rh}$ nanoplates at a low temperature. ${ }^{7 \mathrm{e}}$ Liang and coworkers prepared catalytically active shape selective $\mathrm{Rh}$ nanocubes through a simple photochemical method. ${ }^{7 f}$ More recently, Somorjai's group made sizecontrollable monodisperse (111)-oriented Rh nanocrystals employing a one-step polyol technique, ${ }^{9}$ and obtained monodisperse sub-10 $\mathrm{nm}$ sized $\mathrm{Rh}$ nanocubes in a high selectivity ( $>85 \%$ ) by a seedless polyol method. ${ }^{1 \mathrm{~g}}$ However, there has thus far been no report on the synthesis of monodisperse Rh nanocrystals at a constant size below $10 \mathrm{~nm}$ but with different surface structures by the same synthetic technique, and there is scarce investigation of the shape effects on the catalytic activity and selectivity for those shape-tunable Rh nanocrystals.

In this paper, we report a seedless polyol synthesis of monodisperse sub-10 $\mathrm{nm}$ sized $\mathrm{Rh}$ nanocrystals with (111) and (100) surface structures in ethylene glycol, using rhodium acetate and rhodium chloride as the 
metal precursors. The shape evolution mechanism was carefully explored with various characterization methods including transmission electron microscopy (TEM) and ultraviolet-visible (UV-vis) spectroscopy. The shape evolution from (111)-oriented $\mathrm{Rh}$ nanopolyhedra to (100)-oriented $\mathrm{Rh}$ nanocubes was demonstrated being induced by the selective adsorption of $\mathrm{Br}$ - ions from akylammonium bromides onto the (100) faces of Rh nanocrystals. Using CO oxidation as a model heterogeneous catalytic reaction, the shape effect on the catalytic activity of the (111) and (100)-orientated $\mathrm{Rh}$ nanocrystals was explored, in agreement with previous single crystal studies.

\section{Experimental Section}

1. Chemicals. Rhodium(II) acetate dimer powder ([Rh(Ac) $]_{2}$, Sigma-Aldrich), rhodium(III) chloride hydrate $\left(\mathrm{RhCl}_{3} \cdot x \mathrm{H}_{2} \mathrm{O}\right.$; Sigma-Aldrich), rhodium(III) bromide hydrate $\left(\mathrm{RhBr}_{3} \cdot x \mathrm{H}_{2} \mathrm{O}\right.$; Sigma-Aldrich), rhodium(III) acetylacetonate $\left(\mathrm{Rh}(\mathrm{acac})_{3}, 97 \%\right.$, Sigma-Aldrich), poly(vinylpyrrolidone) (PVP, $M \mathrm{w}=24,000$ and 55,000; Sigma-Aldrich), tetramethylammonium bromide (TMAB, $\left(\mathrm{CH}_{3}\right)_{4} \mathrm{~N}^{+} \mathrm{Br}$, $\geqslant 98.0 \%$, SigmaAldrich), tetraethylammonium bromide (TEAB, $\quad\left(\mathrm{C}_{2} \mathrm{H}_{5}\right)_{4} \mathrm{~N}^{+} \mathrm{Br}, \quad 98.0 \%, \quad$ Sigma-Aldrich), trimethyldodecylammonium bromide (TDAB, $\quad\left(\mathrm{C}_{12} \mathrm{H}_{25}\right) \mathrm{N}^{+}\left(\mathrm{CH}_{3}\right)_{3} \mathrm{Br}-, \quad 99 \%$; Sigma-Aldrich), trimethyl(tetradecyl)ammonium bromide (TTAB, $\left(\mathrm{C}_{14} \mathrm{H}_{29}\right) \mathrm{N}^{+}\left(\mathrm{CH}_{3}\right)_{3} \mathrm{Br}$-, 99\%; Sigma-Aldrich), ethylene glycol (>98\%; EMD), and solvents (analytical grade) including acetone, ethanol, hexanes and chloroform were used without further purification.

2. Synthesis of (111)-Oriented Rh Nanopolyhedra. $0.00625 \mathrm{mmol}\left[\mathrm{Rh}(\mathrm{Ac})_{2}\right]_{2}$ and $0.25 \mathrm{mmol}$ poly(vinylpyrrolidone) $(M \mathrm{w}=55,000$, in terms of the repeating unit) were added to $20 \mathrm{ml}$ ethylene glycol in a $50 \mathrm{ml}$ three-necked flask at room temperature. The stock solution was heated to $100{ }^{\circ} \mathrm{C}$ in a Glas-Col electromantle $(60 \mathrm{~W} ; 50 \mathrm{ml})$ with a Cole-Parmer temperature controller (Diqi-sense $\left.{ }^{\circledR}\right)$, and was evacuated at this temperature for $20 \mathrm{~min}$ to remove water and oxygen under magnetic stirring, resulting in a green solution. The flask was then heated to $185{ }^{\circ} \mathrm{C}$ at $10{ }^{\circ} \mathrm{C} \mathrm{min}^{-1}$, and maintained at this temperature for $2 \mathrm{~h}$ under Ar. When the reaction was complete, an excess of acetone was added at room temperature to form a cloudy black suspension. This suspension was separated by centrifugation at $4200 \mathrm{rpm}$ for $6 \mathrm{~min}$, and the black product was collected by discarding the colorless supernatant. The precipitated Rh nanocrystals were 
washed twice by precipitation/dispersion (re-dispersed in $7.5 \mathrm{ml}$ of ethanol with sonication and then precipitated by adding $37.5 \mathrm{ml}$ of hexanes).

Synthesis of (100)-Oriented Rh nanocubes. The synthetic procedure of Rh nanocubes was the same as that used to synthesize $\mathrm{Rh}$ nanopolyhedra, except that $0.2 \mathrm{mmol} \mathrm{RhCl}_{3}, 1 \mathrm{mmol}$ tetramethylammonium bromide, and $4 \mathrm{mmol}$ poly(vinylpyrrolidone) $(\mathrm{Mw}=24,000$, in terms of the repeating unit) were added to 20 $\mathrm{ml}$ ethylene glycol in a $50 \mathrm{ml}$ three-necked flask at room temperature, which was evacuated at $80{ }^{\circ} \mathrm{C}$ for 20 min, and heated at $185^{\circ} \mathrm{C}$ for $1.5 \mathrm{~h}$.

3. Fabrication of Langmuir-Blodgett (LB) Films. The Rh nanocrystals were washed several times by precipitation/dispersion in ethanol and then in chloroform $(1 \mathrm{ml} \mathrm{Rh}$ suspension was precipitated by adding 4 $\mathrm{ml}$ of hexane, and re-dispersed in $1 \mathrm{ml}$ of ethanol or chloroform with sonication), to remove impurities and excess PVP. Monolayers of Rh nanocrystals were formed by placing drops of Rh nanocrystal chloroform solution onto the water subphase of a LB trough (Nima Technology, M611) at room temperature. ${ }^{1 \mathrm{~g}, 3 \mathrm{a}, 9}$ The surface pressure was monitored with a Wilhelmy plate, and was adjusted to zero before spreading the nanocrystals. The resulting surface layer was compressed by moving the mobile barrier at a rate of $15 \mathrm{~cm}^{2}$ $\mathrm{min}^{-1}$. At different stages of compression, the Rh layers at the water-air interface were carefully transferred onto continuous carbon-coated copper grids using the Langmuir-Schäffer horizontal liftoff method. The surface coverage was evaluated by measuring the particle coverage on selected areas of the TEM grids. The Rh nanocrystals were deposited onto Si wafers $(1 \mathrm{~cm} \times 1 \mathrm{~cm})$ by lift-up of the substrates at a rate of $1 \mathrm{~mm}$ $\min ^{-1}$

4. Characterization Methods. The shape, size and lattice structure of the Rh nanocrystals were analyzed using a Philips FEI Tecnai 12 Transmission electron microscope (TEM) and Philips CM200/FEG high-resolution TEM (HRTEM), operated at 100 and $200 \mathrm{kV}$, respectively. The samples were prepared by placing a drop of Rh nanocrystal sol in ethanol onto a continuous carbon-coated copper TEM grid. The size and shape distribution of the Rh nanocrystals are reported from analysis of at least 50 particles. Powder Xray diffraction (XRD) patterns were recorded on a Bruker D8 GADDS diffractometer using Co-K radiation $_{a}$ ( $\lambda=1.79 \AA$ A $)$. All UV-vis absorption spectra were measured on an Agilent 8453 UV-visible ChemStation 
equipped with a $1 \mathrm{~cm}$ path length quartz cuvette, using samples prepared by diluting $0.1 \mathrm{ml}$ of reaction solution (aspirated directly from the reaction system with a $1 \mathrm{ml}$ plastic syringe) with $5 \mathrm{ml}$ absolute ethanol.

5. CO Oxidation. CO oxidation reactions were performed in a laboratory scale batch reactor with continuous gas recirculation between 170 and $230{ }^{\circ} \mathrm{C}$. Samples were loaded into quartz reactors with a type$\mathrm{K}$ thermocouple touching the reactor near the sample. Prior to the reaction, the manifold was filled with 40 Torr CO (Praxair, UHP), 100 Torr $\mathrm{O}_{2}$ (Praxair, UHP), and a balance of He (Praxair, UHP) initially at atmospheric pressure, all regulated by mass flow controllers. Gas composition was analyzed with a HP 5890 Series II gas chromatograph (GC) equipped with a thermal conductivity (TCD) and a flame ionization (FID) detector. Turnover frequency (TOF) was calculated by extrapolating the conversion data to the initial time and by correcting the Rh surface area for coverage from TEM, and for shape (assuming non-overlapping cubic particles).

\section{Results and Discussion}

\section{Characterization of (111) and (100)-Oriented Rh Nanocrystals.}
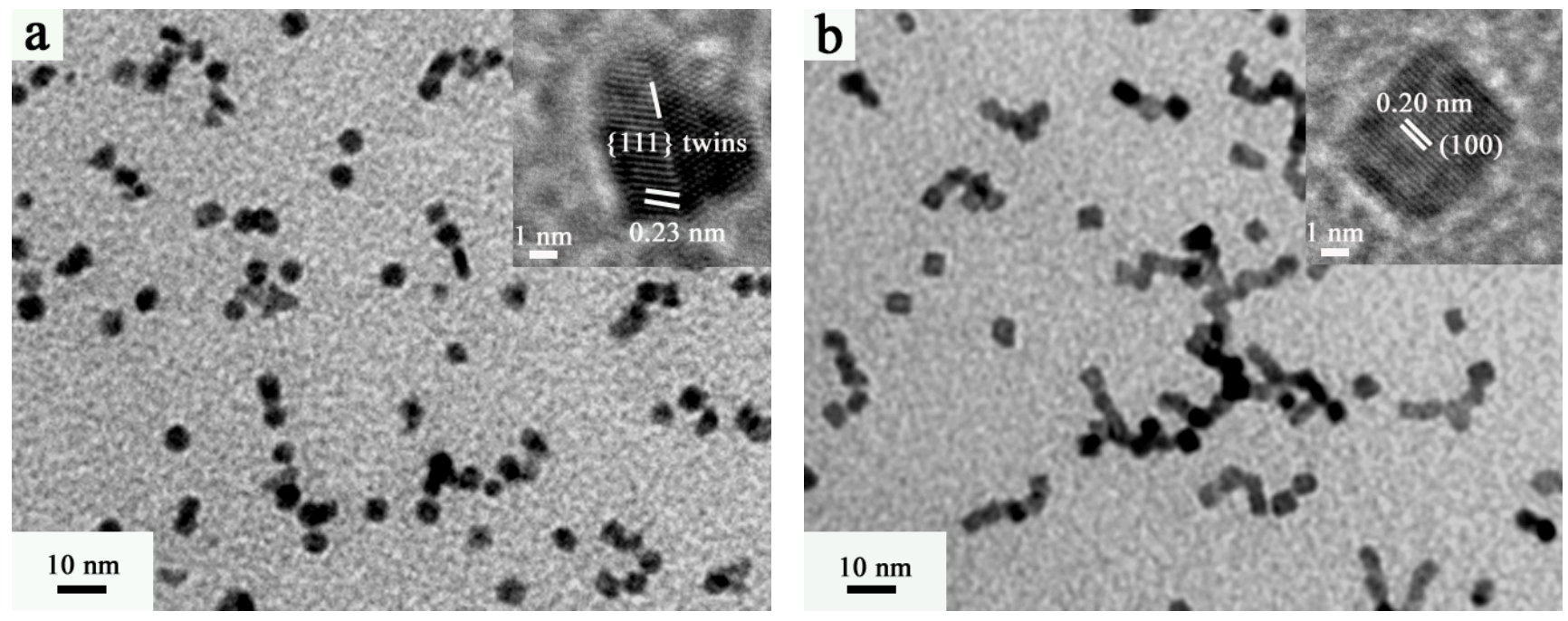
Figure 1. TEM and HRTEM (inset) images of Rh (a) nanopolyhedra and (b) nanocubes synthesized in $20 \mathrm{ml}$ ethylene glycol under an Ar atmosphere: (a) $0.3125 \mathrm{mM}\left[\mathrm{Rh}(\mathrm{Ac})_{2}\right]_{2}, 12.5 \mathrm{mM} \mathrm{PVP}, 185^{\circ} \mathrm{C}, 2 \mathrm{~h}$; (b) $10 \mathrm{mM}$ $\mathrm{RhCl}_{3}, 50 \mathrm{mM}$ TMAB, $200 \mathrm{mM}$ PVP, $185^{\circ} \mathrm{C}, 1.5 \mathrm{~h}$.

We prepared (111)-oriented Rh nanopolyhedra, and (100)-oriented $\mathrm{Rh}$ nanocubes in a size around 6.5 $\mathrm{nm}$ using a seedless polyol method. As seen from the TEM images shown in Figures 1, S1a and S1c, the Rh nanopolyhedra and nanocubes are monodisperse, with sizes of $6.5 \pm 0.6$ and $6.2 \pm 0.6 \mathrm{~nm}$, respectively. The $\mathrm{Rh}$ nanopolyhedra (as observed in 2D projection) are composed of $76 \%$ hexagons (twinned particles), $8 \%$ triangles ((11)-oriented tetrahedra), 11\% squares ((100)-oriented cubes) and 5\% irregular particles (Figures 1a and S1a). The inset in Figure 1a shows a representative HRTEM image of a crystalline hexagon, which is a single twinned particle exposing $\{111\}$ planes (interplanar distance: $0.23 \mathrm{~nm}$ ). The nanocube sample contains $85 \%$ cubes and $15 \%$ irregular particles (Figures $1 \mathrm{~b}$ and S1c). The inset in Figure $1 \mathrm{~b}$ shows a typical HRTEM image of a single-crystalline cube exposing six $\{100\}$ planes (interplanar distance: $0.20 \mathrm{~nm}$ ).

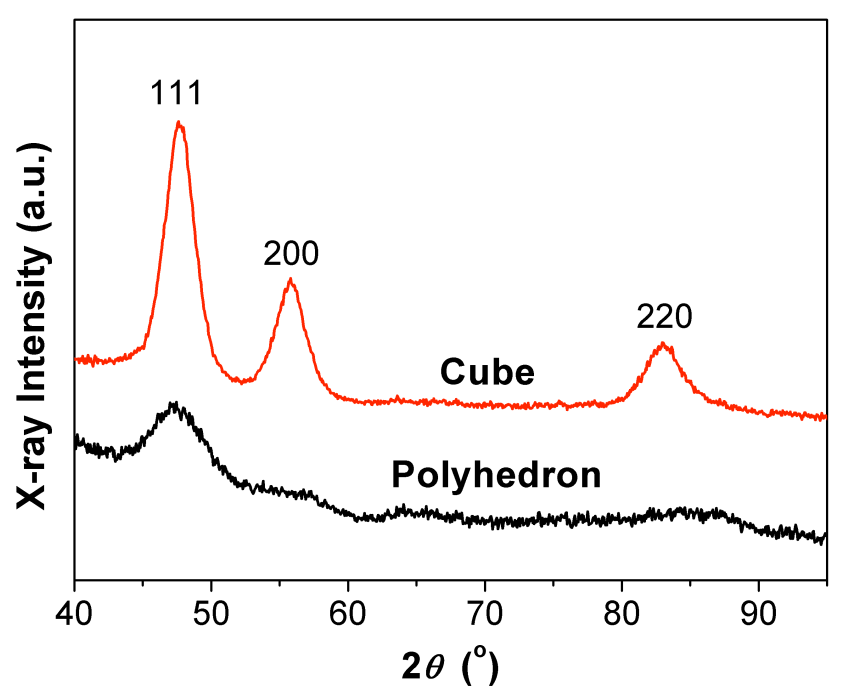

Figure 2. XRD patterns of $\mathrm{Rh}$ nanopolyhedra and nanocubes. 
XRD measurement revealed that both the Rh nanopolyhedra and $\mathrm{Rh}$ nanocubes adopt a face-centeredcubic (fcc) structure with calculated constants of 0.379 and $0.382 \mathrm{~nm}$ (JCPDS: 5-685), respectively. Because of the highly-strained nature and multiply twining of the small fcc structured noble metal nanoparticles, ${ }^{10}$ the line width of the (111) peak for the Rh nanopolyhedra is considerably broader than that for the Rh nanocubes. The ratio of $I_{(111)} / I_{(200)}$ for the Rh nanopolyhedra is 5.3, nearly double of that (2.3) for the Rh nanocubes, indicative of their different surface structures, as also determined from the above HRTEM measurements.

\section{Formation of (111)-Oriented Rh Nanocrystals.}
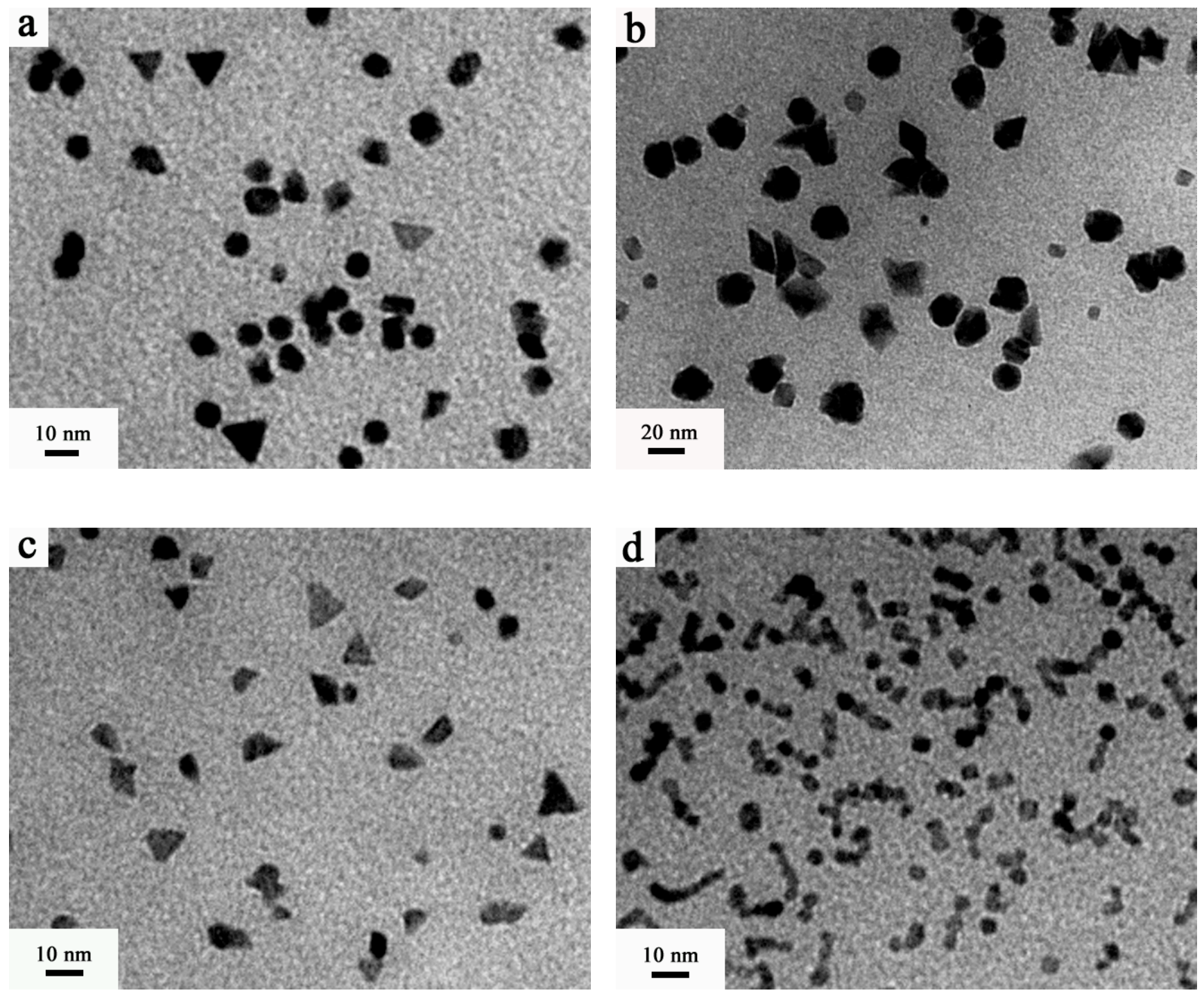
Figure 3. TEM images of Rh nanocrystals synthesized in $20 \mathrm{ml}$ ethylene glycol under an Ar atmosphere: (a) $2.5 \mathrm{mM}\left[\mathrm{Rh}(\mathrm{Ac})_{2}\right]_{2}, 100 \mathrm{mM}$ PVP, $185^{\circ} \mathrm{C}, 2 \mathrm{~h}$; (b) $5 \mathrm{mM} \mathrm{Rh}(\mathrm{acac})_{3}, 50 \mathrm{mM} \mathrm{PVP}, 185{ }^{\circ} \mathrm{C}, 3 \mathrm{~h}$; (c) $5 \mathrm{mM}$ $\mathrm{RhCl}_{3}, 50 \mathrm{mM}$ PVP, $185^{\circ} \mathrm{C}, 2 \mathrm{~h}$; (d) $5 \mathrm{mM} \mathrm{RhBr} 3,50 \mathrm{mM}$ PVP, $185^{\circ} \mathrm{C}, 2 \mathrm{~h}$.

Precursor Effect. The Rh precursor has a large influence on the shape and monodispersity of nanocrystals synthesized in ethylene glycol. At $185{ }^{\circ} \mathrm{C}$, the use of $2.5 \mathrm{mM}\left[\mathrm{Rh}(\mathrm{Ac})_{2}\right]_{2}$ for a $2 \mathrm{~h}$ reaction yielded near-monodisperse Rh nanopolyhedra (40\% hexagons, 14\% pentagons ((111)-twinned decahedra), $25 \%$ triangles, $8 \%$ squares, and $12 \%$ irregular particles $)(9.8 \pm 1.6 \mathrm{~nm}$; Figures $3 \mathrm{a}$ and S1b). The reaction of $\mathrm{Rh}(\mathrm{acac})_{3}$ at $185^{\circ} \mathrm{C}$ for $3 \mathrm{~h}$ formed highly polydisperse $\mathrm{Rh}$ nanopolyhedra (31\% hexagons, $16 \%$ pentagons, $12 \%$ triangles, $22 \%$ squares, and $19 \%$ irregular particles $)(16.9 \pm 6.2 \mathrm{~nm}$; Figure $3 \mathrm{~b})$. The use of $\mathrm{RhCl}_{3}$ for a 2 $\mathrm{h}$ reaction at $185{ }^{\circ} \mathrm{C}$ produced polydisperse $\mathrm{Rh}$ nanocrystals $(30 \%$ triangles, $4 \%$ squares, and $66 \%$ irregular particles) $(8.0 \pm 2.0 \mathrm{~nm}$; Figure $3 \mathrm{c})$; whereas employing $\mathrm{RhBr}_{3}$ under otherwise identical reaction conditions, near-monodisperse Rh nanocrystals containing more nanocubes (41\% squares and 59\% irregular particles) were obtained $(5.6 \pm 0.8 \mathrm{~nm}$; Figure $3 \mathrm{~d})$. These results suggest that $\left[\mathrm{Rh}(\mathrm{Ac})_{2}\right]_{2}$ is the best precursor for the formation of monodisperse (111)-oriented $\mathrm{Rh}$ nanopolyhedra in ethylene glycol, and the introduction of $\mathrm{Br}$ ions into the synthesis enhances the selectivity towards (100)-oriented $\mathrm{Rh}$ nanocubes of a smaller size. ${ }^{1 \mathrm{~g}}$
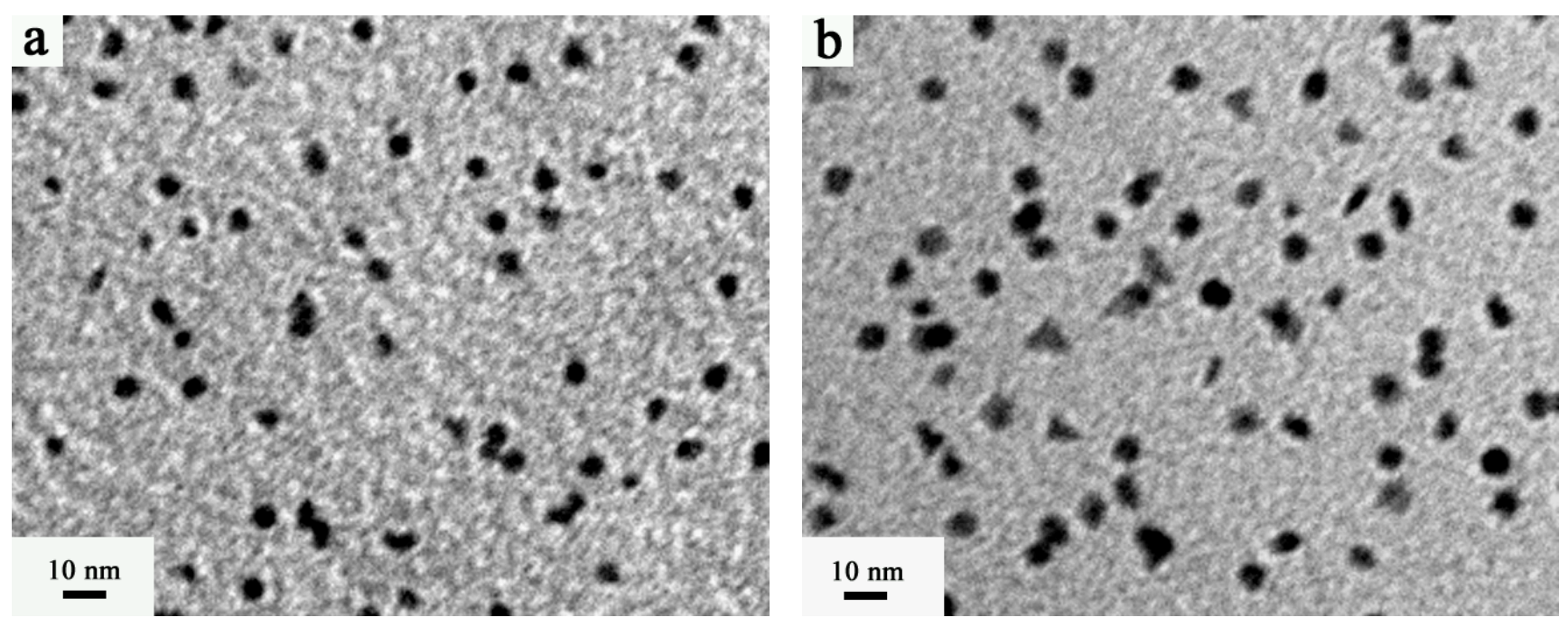

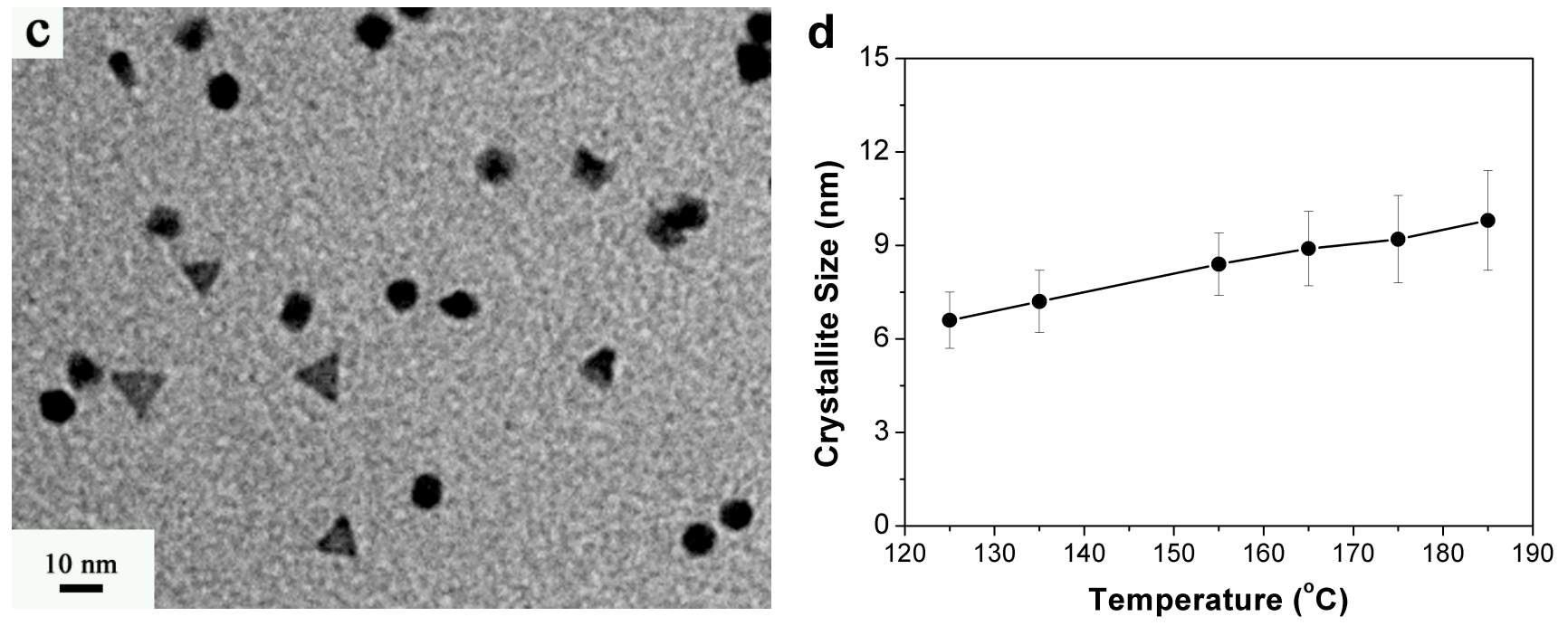

Figure 4. TEM images of Rh nanopolyhedra synthesized in $20 \mathrm{ml}$ ethylene glycol under an Ar atmosphere at different temperatures for $2 \mathrm{~h}$, using $2.5 \mathrm{mM}\left[\mathrm{Rh}(\mathrm{Ac})_{2}\right]_{2}$ and $100 \mathrm{mM}$ PVP: (a) $125{ }^{\circ} \mathrm{C}$; (b) $135{ }^{\circ} \mathrm{C}$; (c) 165 ${ }^{\circ} \mathrm{C}$. (d) Crystallite size of the Rh nanopolyhedra as a function of synthetic temperature.

Temperature Effect. The reduction of $2.5 \mathrm{mM}\left[\mathrm{Rh}(\mathrm{Ac})_{2}\right]_{2}$ at $125{ }^{\circ} \mathrm{C}$ for $2 \mathrm{~h}$ by ethylene glycol resulted in $6.6 \pm 0.9 \mathrm{~nm} \mathrm{Rh}$ nanocrystals (Figure $4 \mathrm{a}$,d). At $135{ }^{\circ} \mathrm{C}$, the nanocrystals were larger $(7.2 \pm 1.0 \mathrm{~nm}$ ) and demonstrated improved faceting (Figure $4 \mathrm{~b}, \mathrm{~d}$ ). With a further increase in reaction temperature, the size of the Rh nanocrystals increased to $8.4 \pm 1.0 \mathrm{~nm}\left(155^{\circ} \mathrm{C}\right)$ and $8.9 \pm 1.2 \mathrm{~nm}\left(165^{\circ} \mathrm{C}\right)$ (Figure $\left.4 \mathrm{c}, \mathrm{d}\right)$. At these elevated temperatures, the nanocrystals were highly-faceted with well-defined shapes (Figure 4c) (30\% hexagons, $15 \%$ pentagons, $17 \%$ triangles, $11 \%$ squares, and $27 \%$ irregular particles). Upon further increase in reaction temperature to $175{ }^{\circ} \mathrm{C}$ and $185{ }^{\circ} \mathrm{C}$, well-shaped $9.2 \pm 1.4$ (Figure $4 \mathrm{~d}$ ) and $9.8 \pm 1.8 \mathrm{~nm}$ (Figure 3a) $\mathrm{Rh}$ nanocrystals, respectively, were obtained. It is noteworthy that the standard deviations of the size distributions for the Rh nanocrystals are all around $15 \%$ in the temperature range of $125-185{ }^{\circ} \mathrm{C}$ (Figure $4 \mathrm{~d}$ ). Increasing reaction temperature results in an increase in the size of the nanocrystals and also promotes the faceting of Rh nanocrystals by developing well-defined edges and corners.

\section{Formation of (100)-Oriented Rh Nanocrystals.}

Effect of Alkylammonium Bromide. It has been demonstrated that, when using $\mathrm{RhCl}_{3}$ as the metal precursor, $\mathrm{Br}$ - ions from various alkylammonium bromides effectively stabilize the $\{100\}$ faces of $\mathrm{Rh}$ 
nanocrystals, and induces the evolution of nanocubes. $6.2 \pm 0.6,6.4 \pm 0.5,6.1 \pm 0.6$, and $6.4 \pm 0.5 \mathrm{~nm} \mathrm{Rh}$ nanocubes with greater than $85 \%$ selectivity were formed from TMAB ( $85 \%$ cubes and $15 \%$ irregular particles; Figure 1b), TEAB (85\% cubes and 15\% irregular particles; Figure 5a), TDAB (87\% cubes and $13 \%$ irregular particles; Figure $5 \mathrm{~b})$ and TTAB (86\% cubes and $15 \%$ truncated cubes; Figures $5 \mathrm{c}, \mathrm{S} 1 \mathrm{~d})$. This suggests that the formation of $\mathrm{Rh}$ nanocubes is due to the stabilization of $\{100\}$ planes by chemically adsorbed $\mathrm{Br}-$ ions, rather than by interactions between the organic ammonium cations and the nanocrystal surfaces. The adsorption of Br species on to the nanocube surface was confirmed by EDS analysis. ${ }^{1 \mathrm{~g}}$ Further, it is observed that the Rh nanocubes prepared from TTAB exhibited well-defined edges and corners (Figures 5c,S1d). As the concentration of $\mathrm{RhCl}_{3}$ and TTAB was decreased by half, slightly truncated $5.8 \pm 0.6 \mathrm{~nm} \mathrm{Rh}$ nanocubes of decreased selectivity (61\% cubes and 39\% irregular particles) were obtained (Figure 5d), possibly owing to the minimization effect of the total surface energy for small nanoparticles. ${ }^{2 c}$
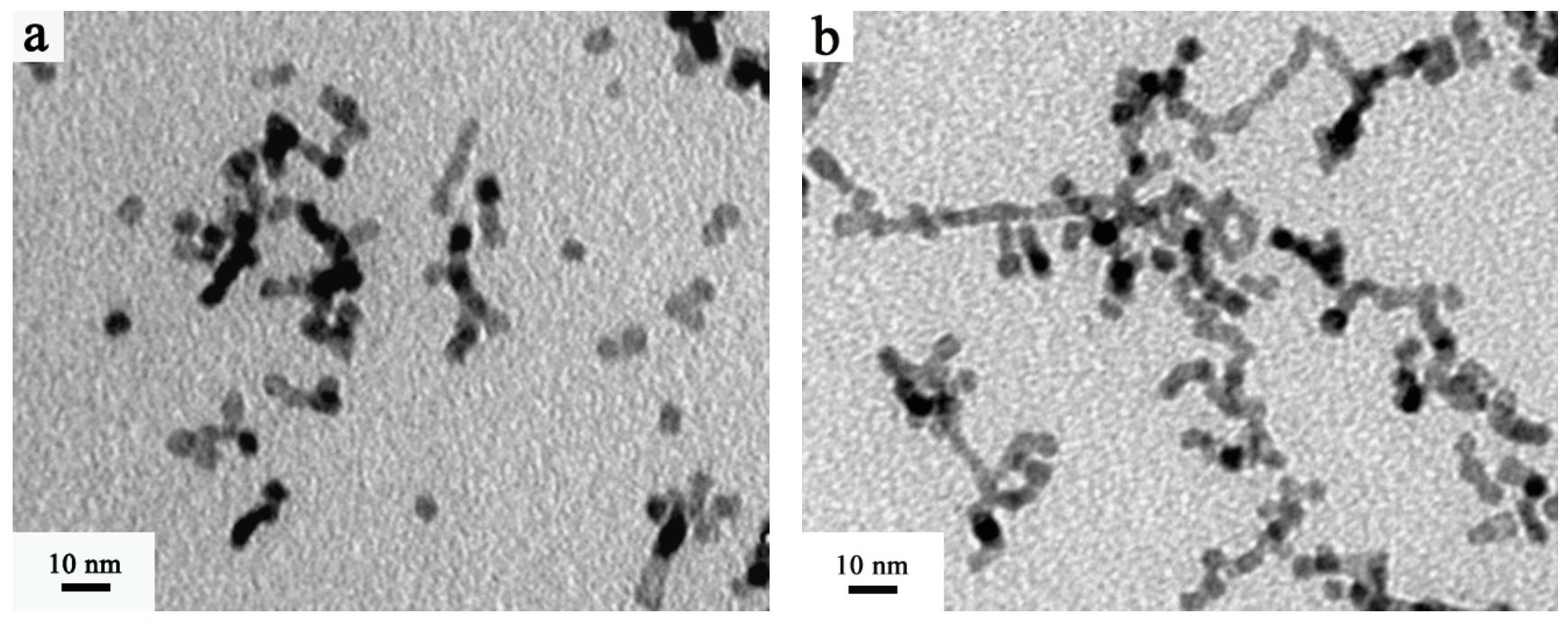

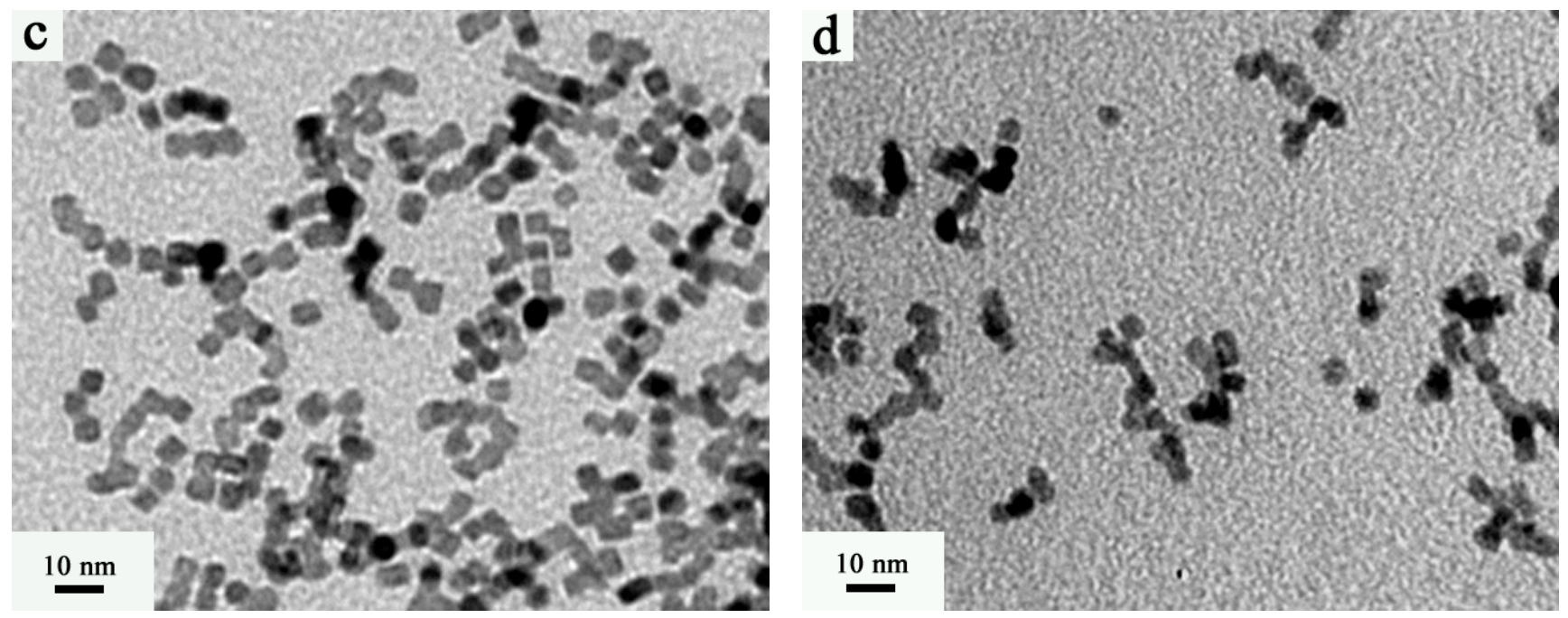

Figure 5. TEM images of $\mathrm{Rh}$ nanocrystals synthesized in $20 \mathrm{ml}$ ethylene glycol under an Ar atmosphere at $185{ }^{\circ} \mathrm{C}$ for $1.5 \mathrm{~h}$ : (a) $10 \mathrm{mM} \mathrm{RhCl}{ }_{3}, 50 \mathrm{mM}$ TEAB, $200 \mathrm{mM}$ PVP; (b) $10 \mathrm{mM} \mathrm{RhCl}{ }_{3}, 50 \mathrm{mM} \mathrm{TDAB}, 200$ mM PVP; (c) $10 \mathrm{mM} \mathrm{RhCl}_{3}, 50 \mathrm{mM}$ TTAB, $200 \mathrm{mM} \mathrm{PVP;} \mathrm{(d)} 5 \mathrm{mM} \mathrm{RhCl}{ }_{3}, 25 \mathrm{mM}$ TTAB, $100 \mathrm{mM} \mathrm{PVP.}$
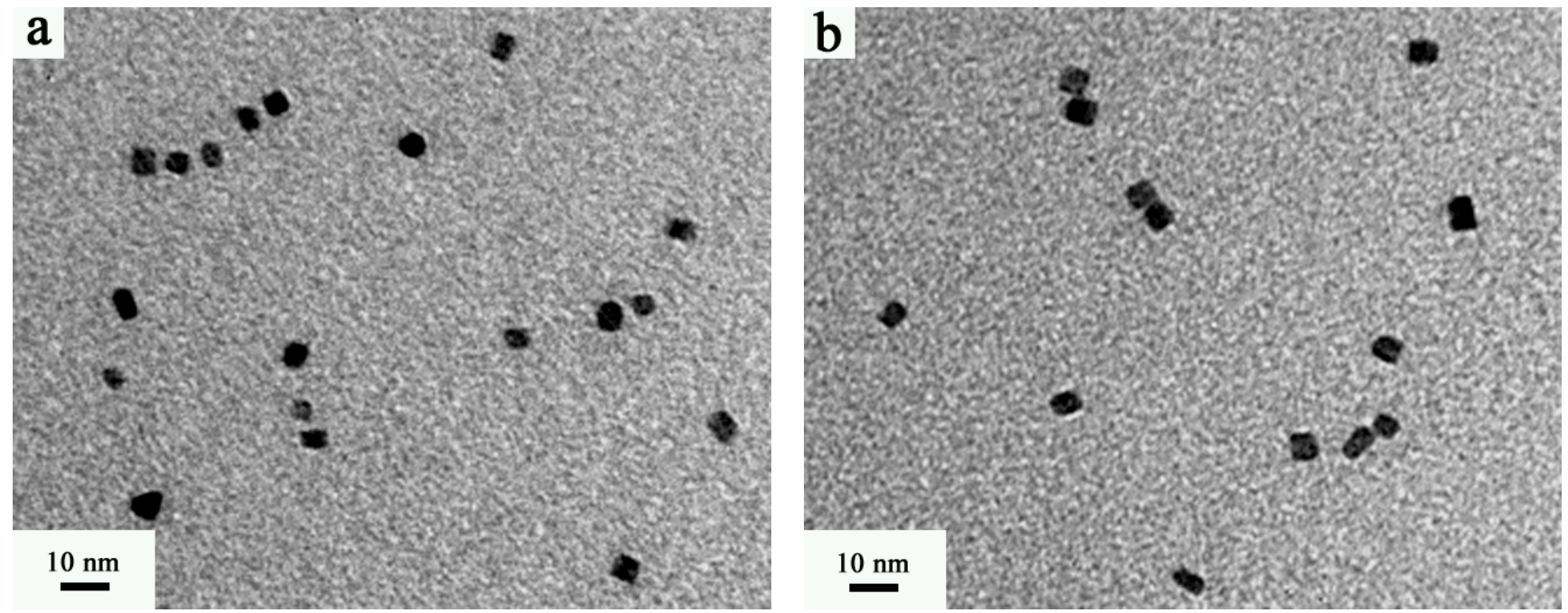

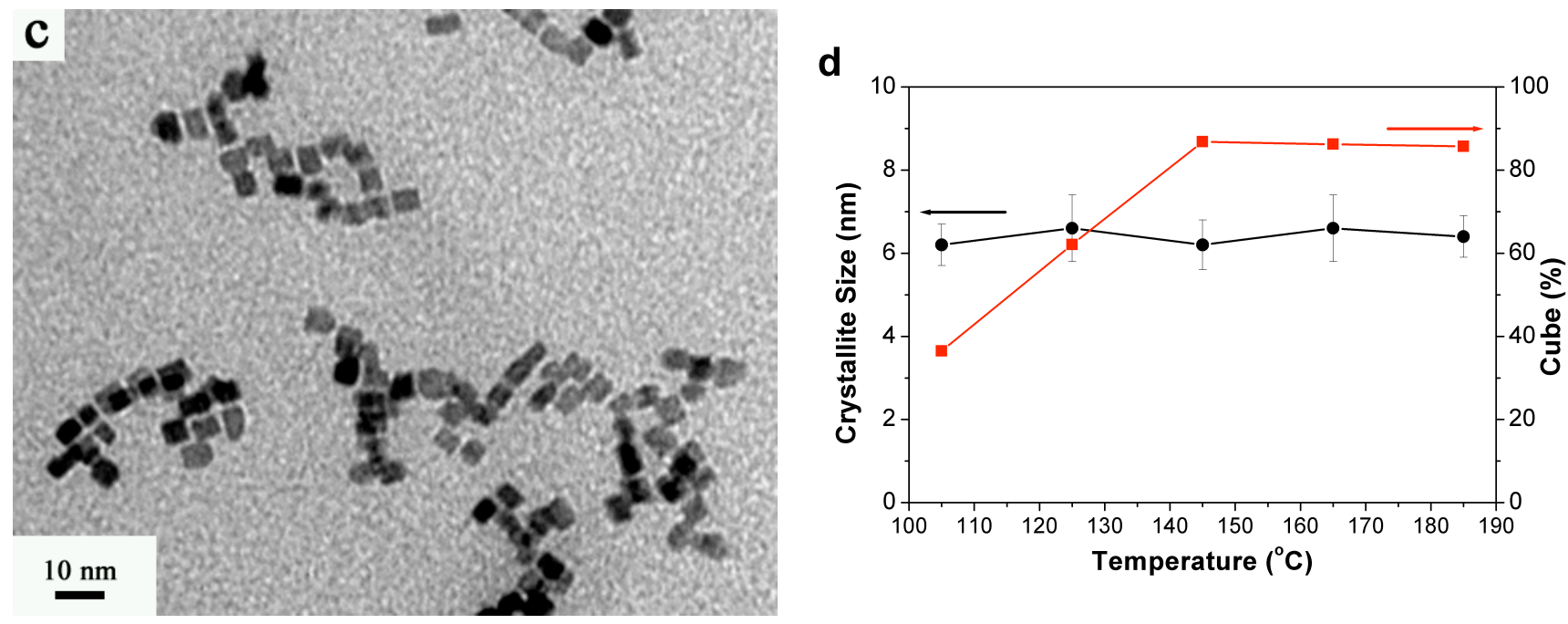

Figure 6. TEM images of $\mathrm{Rh}$ nanocubes synthesized in $20 \mathrm{ml}$ ethylene glycol under an Ar atmosphere at different temperatures for $1.5 \mathrm{~h}$, using $10 \mathrm{mM} \mathrm{RhCl}_{3}, 50 \mathrm{mM}$ TTAB and $200 \mathrm{mM}$ PVP: (a) $105{ }^{\circ} \mathrm{C}$; (b) 125 ${ }^{\circ} \mathrm{C}$; (c) $145^{\circ} \mathrm{C}$. (d) Crystallite size of the Rh nanocubes as a function of synthetic temperature.

Temperature Effect. At a set concentration of $10 \mathrm{mM} \mathrm{RhCl}_{3}$ and $50 \mathrm{mM} \mathrm{TTAB}, 6.2 \pm 0.5,6.6 \pm 0.8$, $6.2 \pm 0.6,6.6 \pm 0.8$, and $6.4 \pm 0.5 \mathrm{~nm} \mathrm{Rh}$ nanocubes were obtained at 105 (Figure 6a), 125 (Figure 6b), 145 (Figure 6c), 165, and $185^{\circ} \mathrm{C}$ (Figures 5c,S1d), respectively. Interestingly, the cube selectivity increased from $37 \%$ at $105{ }^{\circ} \mathrm{C}$, to $62 \%$ at $125{ }^{\circ} \mathrm{C}$, and to $87 \%$ at $145{ }^{\circ} \mathrm{C}$ (Figure $6 \mathrm{~d}$ ). From 145 to $185{ }^{\circ} \mathrm{C}$, the cube selectivity was sustained at a value around $85 \%$ (Figure 6d), and the nanocubes showed straight edges and sharp corners (Figures 5c and 6c). This indicates that the reactions at relatively high temperatures enhance the cube selectivity, and help to develop well-shaped nanocubes.

\section{Shape Control Mechanism of (111) and (100)-Oriented Rh Nanocrystals.}




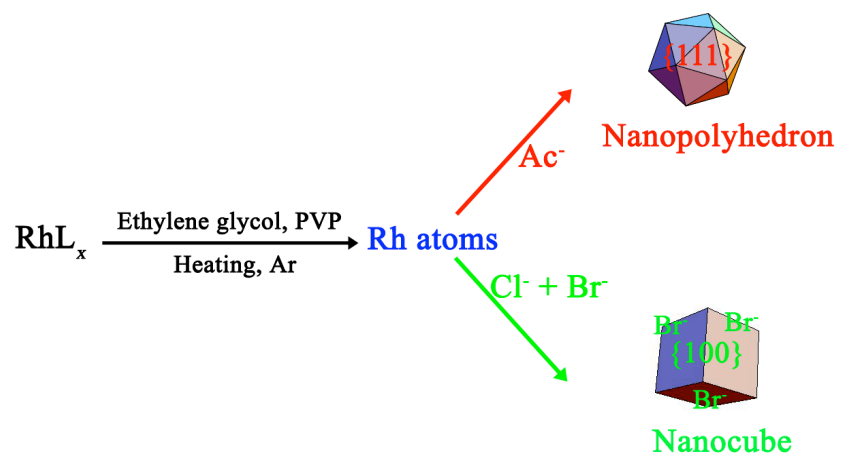

Figure 7. A schematic illustration of the reaction pathways responsible for the formation of (111) and (100)oriented Rh nanocrystals.

Generally, shape control of noble metals is conducted by thermodynamic or kinetic control by tuning the ratio of growth rates along the $<111>$ and $<100>$ directions in various solution phase synthesis via selective adsorption of selective chemical species on a specific crystal plane. ${ }^{1-7,9}$ As is known, for fcc metals, the order of surface energy for different crystal planes is $(111)<(100)<(110)$, thus the (111) surface is the most stable one. Since (111) twinned particles have the lowest free energy, they are thermodynamically favored for fcc noble metals. ${ }^{10}$ Recently, using $\mathrm{Rh}(\mathrm{acac})_{3}$ as the precursor, we obtained size-tunable $(5-15 \mathrm{~nm})$ PVP-capped monodisperse Rh polygonal nanocrystals with the (111) surface structure by a one-step polyol reduction in 1,4-butanediol at temperatures of $170-230{ }^{\circ} \mathrm{C}$ under Ar. ${ }^{9}$ The nanocrystals are composed of hexagons, pentagons and triangles in $2 \mathrm{D}$ projection ( $>65 \%$ in yield), among which, thermodynamicallyfavored twinned particles (hexagons and pentagons) showed a selectivity greater than $45 \%$. In the present work, employing $\left[\left(\operatorname{Rh}(\mathrm{ac})_{2}\right)_{2}\right]$ as the precursor, we obtained $\mathrm{Rh}$ nanopolyhedra dominated by (111)-oriented twinned particles in ethylene glycol at temperatures of $125-185{ }^{\circ} \mathrm{C}$ (Figure 7). In these two approaches, the decomposition of organic ligands in the precursor complexes does not produce strong surface selective adsorbates during the reaction process. As a result, Rh nanocrystals with (111) surface structure were formed, and their sizes were gradually increasing with the reaction temperature from 125 to $185^{\circ} \mathrm{C}$ (see Figure $4 \mathrm{~d}$ ). 


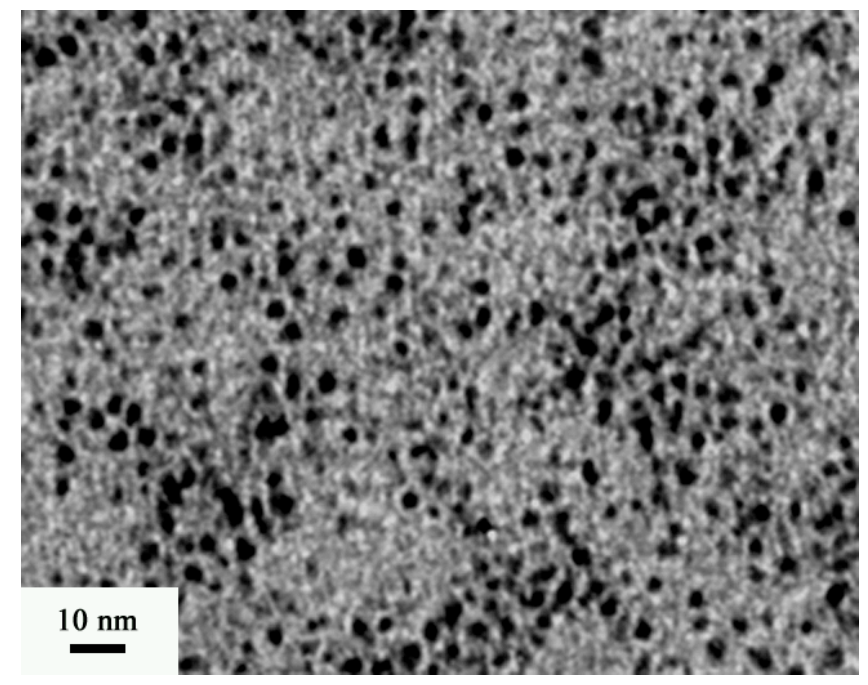

Figure 8. TEM image of Rh nanocrystals synthesized in $20 \mathrm{ml}$ ethylene glycol under an Ar atmosphere at $165{ }^{\circ} \mathrm{C}$ for $1.5 \mathrm{~h}$, using $2.5 \mathrm{mM}\left[\mathrm{Rh}(\mathrm{Ac})_{2}\right]_{2}, 5 \mathrm{mM}$ TMAB, and $50 \mathrm{mM}$ PVP.

Experimentally, we found that the reduction of $\mathrm{RhCl}_{3},\left[\left(\mathrm{Rh}(\mathrm{ac})_{2}\right)_{2}\right]$ and $\mathrm{Rh}(\mathrm{acac})_{3}$ by ethylene glycol started at around $105{ }^{\circ} \mathrm{C}, 125^{\circ} \mathrm{C}$ and $165^{\circ} \mathrm{C}$, respectively. By monitoring the time of the color change from $\mathrm{Rh}$ precursors (light yellow for $\mathrm{RhCl}_{3}$, green for $\left[\left(\mathrm{Rh}(\mathrm{ac})_{2}\right)_{2}\right]$, and orange yellow for $\left.\mathrm{Rh}(\mathrm{acac})_{3}\right)$ to $\mathrm{Rh}$ nanocrystals (black), we found that, at a given temperature, the reduction rates of the precursors follow the trend of $\mathrm{RhCl}_{3}>\left[\left(\mathrm{Rh}(\mathrm{ac})_{2}\right)_{2}\right]>>\mathrm{Rh}(\mathrm{acac})_{3}$. Using these three precursors, (111)-oriented $\mathrm{Rh}$ nanocrystals were formed (Figure 3a,b,c) regardless of the reduction rates of the precursors and the reaction temperatures tested (Figure 4a-c). Thus, (111)-oriented Rh nanocrystals are indeed favored by thermodynamics under conditions where no strongly chemically adsorbed species form on the surface of Rh nanocrystals during crystal growth. However, for these three precursor compounds, monodisperse Rh nanocrystals were only obtained in the case of $\left[\left(\operatorname{Rh}(\mathrm{ac})_{2}\right)_{2}\right]$, possibly due to a balance between nucleation and growth stages achieved in the reduction of $\left[\left(\operatorname{Rh}(\mathrm{ac})_{2}\right)_{2}\right]$ by ethylene glycol. ${ }^{2 \mathrm{c}, \mathrm{d}, 9}$

Further experiments confirmed that the introduction of $\mathrm{Br}$ - ions into the polyol reaction can effectively stabilize the (100) plane of $\mathrm{Rh}$ nanocrystals, since $\mathrm{Br}$-ions tend to be more strongly adsorbed on the (100) plane than on the (111) plane (Figure 7). ${ }^{1 \mathrm{~g}}$ Under this condition, (100)-oriented nanocubes in a high selectivity were formed (Figures $1 \mathrm{~b}, 3 \mathrm{~d}$, and 5), and the size of the nanocubes nearly remains a constant 
value of around $6.5 \mathrm{~nm}$ despite of the elevated reaction temperatures from 105 to $185^{\circ} \mathrm{C}$ because of the rigid growth restriction of the $\{100\}$ facets by the strong adsorption of $\mathrm{Br}$ - ions on them during the synthesis (see Figure 6d). However, in the absence of $\mathrm{Cl}^{-}$ions, poorly-faceted cube-like $\mathrm{Rh}$ nanocrystals were formed (Figure 3d), ${ }^{1 \mathrm{~g}}$ indicating that the presence of $\mathrm{Cl}^{-}$ions assists in developing well-defined $\mathrm{Rh}$ nanocubes (Figures 5 and $6 \mathrm{a}-\mathrm{c})$. In addition, we found that the reaction of $\left[\mathrm{Rh}(\mathrm{Ac})_{2}\right]_{2}$ in the presence of TMAB produced small, irregular and polydisperse $\mathrm{Rh}$ nanoparticles $(4.1 \pm 0.9 \mathrm{~nm}$; Figure 8$)$. Therefore, we concluded that monodisperse $\mathrm{Rh}$ nanocubes were only formed when $\mathrm{RhCl}_{3}$ and alkylammonium bromide were used as the metal precursor and $\mathrm{Br}^{-}$- source, respectively (Figure 7).

From UV-vis spectroscopic measurements, we knew that PVP displays a very strong absorption peak at $208 \mathrm{~nm}$, and $\mathrm{RhBr}_{3}$ has a weak absorption band at $275 \mathrm{~nm}$; while $\mathrm{RhCl}_{3}$ has no clear absorption at $275 \mathrm{~nm}$ (Figure 9). Using $\mathrm{RhCl}_{3}$ and TTAB as the reactants, the appearance of a band at $275 \mathrm{~nm}$ after the reaction solution has been evacuated at $80{ }^{\circ} \mathrm{C}$ for 20 min (Figure 9), indicates that $\left[\left(\mathrm{C}_{14} \mathrm{H}_{29}\right)\left(\mathrm{CH}_{3}\right)_{3} \mathrm{~N}\right]^{+}\left[\mathrm{RhCl}_{4-x} \mathrm{Br}_{x}\right]$ complexes probably form under these conditions. ${ }^{3 \mathrm{c}, 11}$ As the temperature was increased above $100{ }^{\circ} \mathrm{C}$, the band at $275 \mathrm{~nm}$ disappeared (Figure 9) and the color changed from dark brown to black, indicating the complete reduction of $\mathrm{Rh}$ monomers. From further TEM characterizations, we knew that $6.2 \pm 0.5 \mathrm{~nm} \mathrm{Rh}$ nanocubes in a selectivity of $47 \%$ were formed at $105{ }^{\circ} \mathrm{C}$ (Figure 6a), indicating that there exists strong bonding interactions between the $\mathrm{Rh}$ nuclei and $\mathrm{Br}$ - ions from alkylammonium bromide in the reaction solution. During the nanocube growth process, chemically adsorbed $\mathrm{Br}^{-}$species not only stabilize the (100) face, but also restrain the particle growth rate. Therefore, the use of different alkylammonium bromides produced sub-10 nm sized $\mathrm{Rh}$ nanocubes, all in sizes close to $6.5 \mathrm{~nm}$, regardless of the hydrocarbon chain length of the surfactants and the reaction temperatures. Furthermore, the formation of Rh nanocubes between 105 to $185{ }^{\circ} \mathrm{C}$ by the addition of alkylammonium bromide in the polyol reduction suggests that $\mathrm{Rh}$ nanocubes are the thermodynamically-favored products under these conditions. 


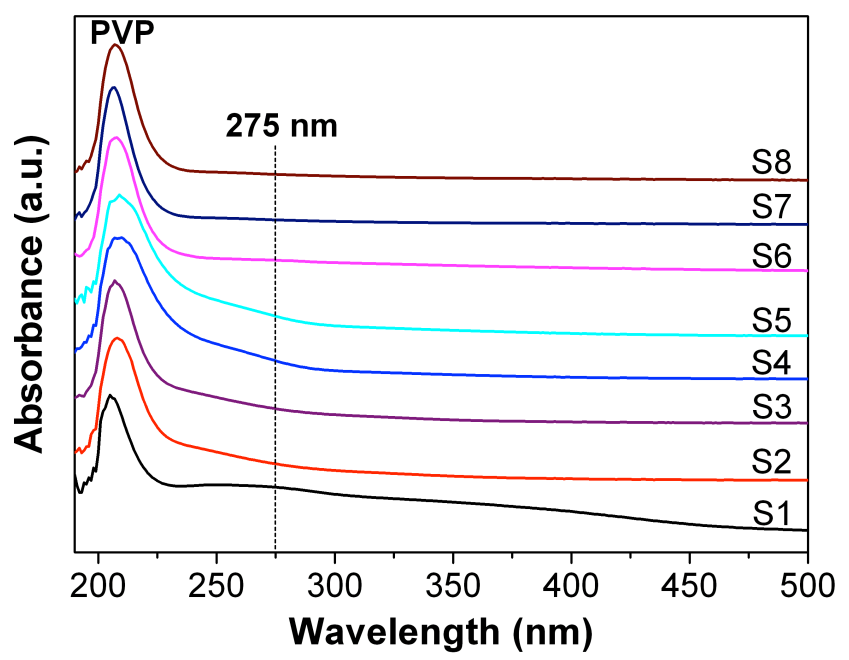

Figure 9. UV-Vis spectra of the Rh samples taken at different conditions: S1: ethylene glycol solution containing $\mathrm{RhBr}_{3}$ and PVP; S2: ethylene glycol solution containing $\mathrm{RhCl}_{3}$ and PVP; S3: ethylene glycol solution containing $10 \mathrm{mM} \mathrm{RhCl}_{3}, 50 \mathrm{mM}$ TTAB and $200 \mathrm{mM}$ PVP without further processing; S4: sample taken from the reaction solution (ethylene glycol solution containing $10 \mathrm{mM} \mathrm{RhCl} 3,50 \mathrm{mM}$ TTAB and 200 mM PVP) after 20 min evacuation at $80{ }^{\circ} \mathrm{C}$; S5: sample taken from the reaction solution at $100{ }^{\circ} \mathrm{C}$; S6: sample taken from the reaction solution at $185^{\circ} \mathrm{C}$; S7: sample taken from the reaction solution after $45 \mathrm{~min}$ at $185^{\circ} \mathrm{C}$; S8: sample taken from the reaction solution after $1.5 \mathrm{~h}$ at $185^{\circ} \mathrm{C}$.

\section{CO-O $\mathrm{O}_{2}$ Reactions with (111) and (100)-Oriented Rh Nanocrystals.}

With a LB trough, the as-obtained $6.5 \mathrm{~nm} \mathrm{Rh}$ nanopolyhedra and nanocubes were deposited onto silicon wafers to form $2 \mathrm{D}$ catalytic nanoarray monolayers, which were then tested for $\mathrm{CO}$ oxidation activity between 170 and $230{ }^{\circ} \mathrm{C}$. Four (111) and (100)-oriented $\mathrm{Rh}$ nanocatalysts at a constant size of $\sim 6.5 \mathrm{~nm}$ were synthesized by our seedless polyol method, and were denoted as Rh-1 $\left(0.3125 \mathrm{mM}\left[\mathrm{Rh}(\mathrm{Ac})_{2}\right]_{2}\right.$ and $12.5 \mathrm{mM}$ PVP in $20 \mathrm{ml}$ ethylene glycol under Ar at $185{ }^{\circ} \mathrm{C}$ for $\left.2 \mathrm{~h}\right)$, $\mathbf{R h}-2\left(0.625 \mathrm{mM} \mathrm{Rh}(\mathrm{acac})_{3}\right.$ an $6.25 \mathrm{mM}$ PVP in 1,4-butanediol under Ar at $225{ }^{\circ} \mathrm{C}$ for $\left.2 \mathrm{~h}\right),{ }^{9} \mathbf{R h}-3\left(10 \mathrm{mM} \mathrm{RhCl}_{3}, 50 \mathrm{mM}\right.$ TMAB and $200 \mathrm{mM}$ PVP in $20 \mathrm{ml}$ ethylene glycol under $\mathrm{Ar}$ at $185{ }^{\circ} \mathrm{C}$ for $\left.1.5 \mathrm{~h}\right)$, and $\mathbf{R h}-4\left(10 \mathrm{mM} \mathrm{RhCl}_{3}, 50 \mathrm{mM}\right.$ TTAB and $200 \mathrm{mM}$ PVP in $20 \mathrm{ml}$ ethylene glycol under $\mathrm{Ar}$ at $185{ }^{\circ} \mathrm{C}$ for $1.5 \mathrm{~h}$ ). Turnover frequency (TOF) was calculating by extrapolating the conversion data to the initial time and by correcting the $\mathrm{Rh}$ surface area for coverage from 
TEM and SEM, and for shape (assuming non-overlapping cubic particles). The SEM measurements indicated that the as-deposited $\mathrm{Rh}$ nanocrystals in the monolayer remain intact and do not aggregate before and after reaction. ${ }^{13}$ For the samples of $\mathbf{R h}-\mathbf{1}, \mathbf{R h}-\mathbf{2}, \mathbf{R h}-\mathbf{3}$, and $\mathbf{R h}-\mathbf{4}$, the geometric sizes were $6.5 \pm 0.6$, $6.3 \pm 0.6,6.2 \pm 0.6$, and $6.4 \pm 0.5 \mathrm{~nm}$, respectively, and the numbers of the calculated surface $\mathrm{Rh}$ atoms were 2.9 $\times 10^{15}, 2.3 \times 10^{15}, 4.4 \times 10^{15}$, and $3.9 \times 10^{15}$, respectively. The combined results from X-ray photoelectron spectroscopy (XPS) and energy dispersive X-ray analysis (EDAX) have demonstrated that PVP molecules were more strongly adsorbed to the Rh nanocube surfaces after washing treatment and a small fraction of $\mathrm{Br}$ species were present on the nanocube surfaces along with the PVP molecules. ${ }^{\text {lg }}$

Catalytic tests have demonstrated that all the four catalysts were active for the $\mathrm{CO}-\mathrm{O}_{2}$ reaction between 170 and $230{ }^{\circ} \mathrm{C}$. At $200{ }^{\circ} \mathrm{C}$, the turnover frequencies (TOF) of Rh-1, Rh-2, Rh-3, and Rh-4 (Ref. 1g) are 5.5, 4.3, 3.9, and $2.1 \mathrm{~s}^{-1}$ (Table 1), respectively, comparable to those reported for $\mathrm{Rh}(111)$ and $\mathrm{Rh}(100)$ single crystals. ${ }^{12}$ For the $\mathrm{CO}-\mathrm{O}_{2}$ reaction, Rh-1, Rh-2, Rh-3, and $\mathbf{R h}-\mathbf{4}$ have apparent activation energies of 30, 32, 31 and $35 \mathrm{kcal} \mathrm{mol}^{-1}$ (Table 1), respectively, indicating that this reaction is structure insensitive for the asobtained $6.5 \mathrm{~nm}$ (111)-orientated $\mathrm{Rh}$ nanopolyhedra and (100)-oriented nanocubes, just the same as that observed for $\mathrm{Rh}(111)$ and $\mathrm{Rh}(100)$ single crystals. ${ }^{1 \mathrm{~g}, 12}$ However, presumably owing to the adsorption of capping ligands on the nanocrystal surfaces, the four Rh nanocatalysts show somewhat higher apparent activation energies for $\mathrm{CO}$ oxidation than those $\left(25.4 \mathrm{kcal} \mathrm{mol}^{-1}\right)$ reported for $\mathrm{Rh}(111)$ and $\mathrm{Rh}(100)$ single crystals. ${ }^{12}$ More recently, we have found a shape dependent selectivity in the reduction of NO by CO with the as-prepared (111)-orientated Rh nanopolyhedra and (100)-oriented nanocubes. ${ }^{14}$

\section{Conclusions}

We have developed a selective synthesis of monodisperse PVP-capped sub-10 nm $(6.5 \mathrm{~nm}) \mathrm{Rh}$ nanocrystals with (111) and (100) surface structures, through a seedless polyol reduction in ethylene glycol. The (111)-oriented $\mathrm{Rh}$ nanopolyhedra dominated by (111)-twined hexagons (observed in 2D projection) were synthesized using $\left[\mathrm{Rh}(\mathrm{Ac})_{2}\right]_{2}$ as the metal precursor; whereas, the (100)-oriented Rh nanocubes were obtained in the presence of alkylammonium bromides (e.g., tetramethylammonium bromide, trimethyl(tetradecyl)ammonium bromide), employing $\mathrm{RhCl}_{3}$ as the metal precursor. The evolution of $\mathrm{Rh}$ 
nanocubes was induced from the effective stabilization of $\{100\}$ faces by chemically adsorbed $\mathrm{Br}$ - ions from alkylammonium bromides. The (111)-oriented Rh nanopolyhedra and (100)-oriented Rh nanocubes were deposited onto silicon wafers to form 2D model nanoarray catalysts with a Langmuir-Blodgett trough. Catalytic measurements showed that these nanocatalysts were active for $\mathrm{CO}-\mathrm{O}_{2}$ reaction, and the turnover frequency is structure insensitive, in agreement with previous findings for $\mathrm{Rh}(111)$ and $\mathrm{Rh}(100)$ single crystals.

Supporting Information Available: More TEM images of as-synthesized Rh nanocrystals (Figure S1) are included in supporting information. This material is available free of charge via the Internet at http://pubs.acs.org.

Acknowledgements. This work was supported by the Director, Office of Science, Office of Basic Energy Sciences, Division of Chemical Sciences, Geological and Biosciences and Division of Materials Sciences and Engineering of the U.S. Department of Energy under Contract No. DE-AC02-05CH11231. We thank the Berkeley Electron Microscopy Lab and National Center for Electron Microscopy for the use of their TEM and HRTEM facilities, and also thank Prof. A. Paul Alivisatos for the use of the powder X-ray diffractometer. Y.W.Z. appreciates the financial aid of Huaxin Distinguished Scholar Award from Peking University Education Foundation of China. 


\section{References and Notes}

(1) (a) Ahmadi, T. S.; Wang, Z. L.; Green, T. C.; Henglein, A.; El-Sayed, M. A. Science 1996, 272, 1924. (b) Tian, N.; Zhou, Z. Y.; Sun, S. G.; Ding, Y.; Wang, Z. L. Science 2007, 316, 732. (c) Bratlie, K. M.; Lee, H., Komvopoulos, K.; Yang, P.; Somorjai; G. Nano Lett. 2007, 7, 3097. (d) Habas, S. E.; Lee, H.; Radmilovic, V.; Somorjai, G. A.; Yang, P. Nature Mater. 2007, 6, 692. (e) Lee, H.; Susan, E. H.; Somorjai, G. A.; Yang, P. J. Am. Chem. Soc. 2008, 130, 5406. (f) Wang, C.; Daimon, H.; Onodera, T; Koda, T.; Sun, S. Angew. Chem. Int. Ed. 2008, 47, 3588. (g) Zhang, Y.; Grass, M. E.; Kuhn, J. N.; Tao, F.; Habas, S. E.; Huang W.; Yang, P.; Somorjai, G. A. J. Am. Chem. Soc. 2008, 130, 5868. (h) Nolte, P.; Stierle, A.; Jin-Phillipp, N. Y.; Kasper, N.; Schulli, T. U.; Dosch, H. Science 2008, 321, 1654. (i) Somorjai, G. A.; Park, J. Y. Angew. Chem. Int. Ed. 2008, 47, 9212. (j) Somorjai, G. A.; Frei, H., Park, J. Y. J. Am. Chem. Soc. 2009, 131, 16589. (k) Tsung, C.-K.; Kuhn, J. N.; Huang, W.; Aliaga, C.; Hung, L.; Somorjai, G. A.; Yang, P. J. Am. Chem. Soc. 2009, 131, 5816. (1) Zeng, J.; Zhang, Q.; Chen, J.; Xia, Y. Nano Lett. 2010, 10, 30.

(2) (a) Narayanan, R.; El-Sayed, M. A. J. Phys. Chem. B 2005, 109, 12663. (b) Somorjai, G. A.; Park, J. Y. J. Chem. Phys. 2008, 128, 182504. (c) Tao, A. R.; Habas, S.; Yang, P. Small 2008, 4, 310. (d) Xiong, Y.; Xia, Y. Adv. Mater. 2007, 19, 3385.

(3) (a) Song, H.; Kim, F.; Connor, S.; Somorjai, G. A.; Yang, P. J. Phys. Chem. B 2005, 109, 188. (b) Chen, J.; Herricks, T.; Xia, Y. Angew. Chem. Int. Ed. 2005, 44, 2589. (c) Lee, H.; Habas, S. E.; Kweskin, S., Butcher, D.; Somorjai, G. A.; Yang, P. Angew. Chem. Int. Ed., 2006, 45, 7824.

(4) (a) Xiong, Y.; Chen, J.; Benjamin, J. W.; Xia, Y.; Aloni, S.; Yin, Y. J. Am. Chem. Soc. 2005, 127, 7332.

(b) Xiong, Y., McLellan, J. M.; Yin, Y; Xia, Y. Angew. Chem. Int. Ed. 2007, 46, 790. (c) Xiong, Y.; Cai, H.; Wiley, B. J.; Wang, J.; Kim, M. J.; Xia, Y. J. Am. Chem. Soc. 2007, 129, 3665.

(5) (a) Tao, A.; Sinsermsuksakul, P.; Yang, P. Angew. Chem. Int. Ed. 2006, 45, 4597. (b) Chen, S; Carroll, D. L. J. Phys. Chem. B 2004, 108, 5500. 
(6) (a) Seo, D.; Park, J. C.; Song, H. J. Am. Chem. Soc. 2006, 128, 14863. (b) Wu, H.-Y.; Liu, M.; Huang, M. H. J. Phys. Chem. B 2006, 110, 19291.

(7) (a) Zettsu, N.; McLellan, J. M.; Wiley, B.; Yin, Y.; Li, Z.-Y.; Xia, Y. Angew. Chem. Int. Ed. 2006, 45, 1288. (b) Humphrey, S. M.; Grass, M. E.; Habas, S. E.; Niesz, K.; Somorjai, G. A.; Tilley, T. D., Nano Lett. 2007, 7, 785. (c) Hoefelmeyer, J. D.; Niesz, K.; Somorjai, G. A.; Tilley, T. D. Nano Lett. 2005, 5, 435. (d) Park, K. H.; Jang, K.; Kim, H. J.; Son, S. U. Angew. Chem. Int. Ed. 2007, 46, 1152. (e) Jang, K.; Kim, H. J.; Son, S. U. Chem. Mater. 2010, 22, 1273. (f) Kundu, S.; Wang, K.; Liang, H. J. Phys. Chem. C 2009, 113, 18570 .

(8) (a) Pellegatta, J.-L.; Blandy, C.; Collière, V.; Choukroun, R.; Chaudret, B.; Cheng P.; Philippot, K. J. Mol. Catal. A 2002, 178, 55. (b) Yoon, T.-J.; Kim, J. I.; Lee J.-K. Inorg. Chim. Acta 2003, 345, 228. (c) Halttunen, M. E.; Niemelä, M. K.; Krause, A.O.I.; Vaara, T.; Vuori, A.I. Appl. Catal. A 2001, 205, 37. (d) Gayen, A.; Baidya, T.; Biswas, K.; Roy, S.; Hegde, M.S. Appl. Catal. A 2006, 315, 135. (e) Pan H.B.; Wai, C. M. J. Phys. Chem. C 2009, 113, 19782.

(9) Zhang, Y.; Grass, M. E.; Habas, S. E.; Tao, F.; Zhang, T.; Yang, P.; Somorjai, G. A. J. Phys. Chem. C 2007, 111, 12243.

(10) (a) Wang, Z. L. J. Phys. Chem. B 2000, 104, 1153. (b) Marks, L. D. Rep. Prog. Phys. 1994, 57, 603.

(11) Veisz, B.; Király, Z. Langmuir 2003, 19, 4817.

(12) Peden, C. H. F.; Goodman, D. W.; Blair, D. S.; Berlowitz, P. J.; Fisher, G. B.; Oh, S. H. J. Phys. Chem. 1988, 92, 1563.

(13) Grass, M. E.; Zhang, Y.; Butcher, D. R.; Park, J. Y.; Li, Y.; Bluhm, H.; Bratlie, K. M.; Zhang, T.; Somorjai, G. A. Angew. Chem. Int. Ed. 2008, 47, 8893.

(14) Renzas, J. R.; Zhang, Y.; Huang, W.; Somorjai, G. A. Catal. Lett. 2009, 132(3-4), 317. 
TABLE 1: CO-O 2 Turnover Frequency (TOF), Activation Energy (Ea) for the LB Monolayers of (111) and (100) Oriented Rh Nanocrystals on Silicon Wafers

\begin{tabular}{|c|c|c|c|c|c|c|}
\hline & Shape & Size (nm) & Orientation & Coverage $^{\mathrm{a}}$ & $\mathrm{Ea}\left(\mathrm{kcal} \mathrm{mol}{ }^{-1}\right)$ & $\mathrm{TOF}^{\mathrm{b}}$ at $200^{\circ} \mathrm{C}\left(\mathrm{s}^{-1}\right)$ \\
\hline $\mathrm{Rh}-1$ & Polyhedron & $6.5 \pm 0.6$ & $(111)$ & 0.37 & 30 & 5.5 \\
\hline $\mathrm{Rh}-2^{\mathrm{c}}$ & Polyhedron & $6.3 \pm 0.6$ & $(111)$ & 0.19 & 32 & 4.3 \\
\hline Rh-3 & Cube & $6.2 \pm 0.6$ & $(100)$ & 0.56 & 31 & 3.9 \\
\hline $\mathrm{Rh}-4$ & Cube & $6.4 \pm 0.5$ & $(100)$ & 0.39 & 35 & 2.1 (Ref. 1g) \\
\hline \multicolumn{7}{|c|}{${ }^{\text {a }}$ Coverage determined from a $1 \mu \mathrm{m} \times 1 \mu \mathrm{m}$ area of a TEM grid lifted from LB trough. ${ }^{\mathrm{b}}$ Surface $\mathrm{Rh}$ atoms } \\
\hline \multicolumn{7}{|c|}{ were determined from geometric considerations. Reaction conditions were 40 Torr $\mathrm{CO}, 100$ Torr $\mathrm{O}_{2}, 170$} \\
\hline \multicolumn{7}{|c|}{$230{ }^{\circ} \mathrm{C} .{ }^{\mathrm{c}}$ Prepared from $0.625 \mathrm{mM} \mathrm{Rh}(\mathrm{acac})_{3}$ and $6.25 \mathrm{mM} \mathrm{PVP}$ in 1,4-butanediol under Ar at $225^{\circ} \mathrm{C}$ for 2} \\
\hline
\end{tabular}


Table of Contents

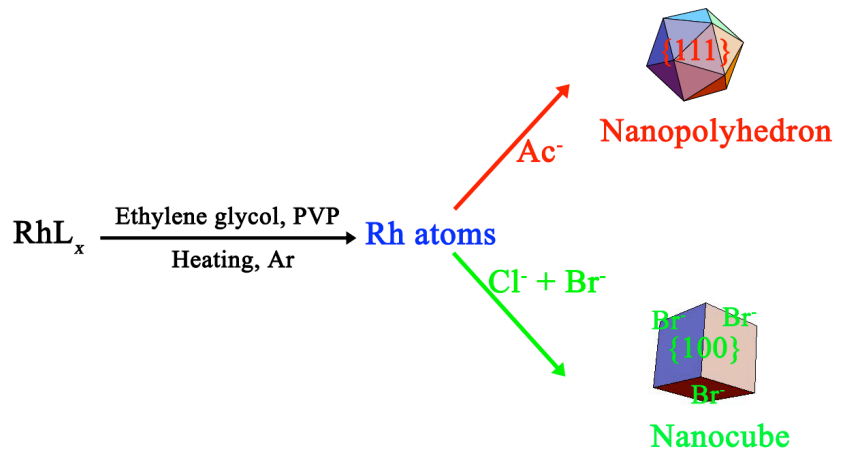




\section{LEGAL DISCLAIMER}

This document was prepared as an account of work sponsored by the United States Government. While this document is believed to contain correct information, neither the United States Government nor any agency thereof, nor The Regents of the University of California, nor any of their employees, makes any warranty, express or implied, or assumes any legal responsibility for the accuracy, completeness, or usefulness of any information, apparatus, product, or process disclosed, or represents that its use would not infringe privately owned rights. Reference herein to any specific commercial product, process, or service by its trade name, trademark, manufacturer, or otherwise, does not necessarily constitute or imply its endorsement, recommendation, or favoring by the United States Government or any agency thereof, or The Regents of the University of California. The views and opinions of authors expressed herein do not necessarily state or reflect those of the United States Government or any agency thereof or The Regents of the University of California. 